2 Hirsch M, Shemesh J, Modan M, Lunenfeld B. Emission of spermatozoa, age of onset. Int f Androl 1979; 2: 289-98. Kulin HE, Frontera MA, Demers LM, Bartholomew MJ, Lloyd TA. The onset of sperm production in pubertal boys. Relationship to gonadotropin excretion. $\mathrm{Am} \mathcal{F} \mathrm{Dis}$ Child 1989; 143: 190-3.

4 Schaefer F, Marr J, Seidel C, Tilgen W, Scharer K. Assessment of gonadal maturation by evaluation of spermaturia. Arch Dis Child 1990; 65: 1205-7.

5 Hirsch M, Lunenfeld B, Modan M, Ovadia J, Shemesh J. Spermarche - the age of onset of sperm emission. $\dot{f}$ Adolesc Health Care 1985; 5: 35-9.

6 Richardson DW, Short RV. Time of onset of sperm production in boys. $\mathcal{f}$ Biosoc Sci Suppl 1978; 5: 15-25.

7 Baldwin BT. The determination of sex maturation in boys by a laboratory method. $f$ Comp Psychol 1928; 8: 39-43.
8 Weissenberg $R$, Rozenman $H$, Hova $M$, Modan $M$, Lunenfeld $\mathbf{B}$. The diagnostic value of sperm in postLunenfeld $B$. The diagnostic value of sperm
ejaculatory urine. Int $\mathcal{f}$ Androl $1984 ; 7: 142-8$.

9 Carlier JG, Steeno OP. Oigarche: the age at first ejaculation. Andrologia 1985; 17: 104-6.

10 Laron Z, Arad J, Gurewitz R, Grunebaum M, Dickerman $Z$. Age at first conscious ejaculation: a milestone in male puberty. Helvetica Paediatrica Acta 1980; 35: 13-20.

11 Tanner JM. Growth at adolescence. Oxford: Blackwell, 1962.

12 Prader A. Testicular size: assessment and clinical importance. Triangle 1966; 7: 240-3.

13 Mood AM. The distribution theory of run's. Annals of Mathematical Statistics 1940; 11: 367-92.

14 Johnson L. A re-evaluation of daily sperm output of men. Fertil Steril 1982; 37: 811-6.

15 Wilhelm SF, Seligmann AW. Spermatozoa in urine. $A m \mathcal{F}$ Surg 1937; 35: 572-4.

\title{
Newborns find too much prostaglandin hard to stomach
}

Infusion of prostaglandin $\mathrm{E}_{1}$, in newborn babies to keep the ductus arteriosus open in congenital heart disease, or to treat persistent fetal circulation or pulmonary hypertension, may cause gastric antral obstruction. Workers in Toronto (Nathan Peled and colleagues, New England fournal of Medicine 1992; 327: 505-10) noticed antral mucosal thickening in two term babies, one with a hypoplastic left ventricle and pulmonary valvular dysplasia and one with pulmonary hypertension. They therefore reviewed the notes of all neonates treated with prostaglandin $\mathrm{E}_{1}$ at the Hospital for Sick Children, Toronto over a two year period beginning on 1 October 1989. Of the 74 babies in the study five were shown to have antral mucosal hyperplasia either on ultrasound scan $(n=3)$, at necropsy $(n=1)$, or by both ultrasound and necropsy $(n=1)$. Four other babies had clinical features suggesting antral obstruction but no ultrasound or necropsy confirmation of antral hyperplasia. The five babies with proved antral hyperplasia were slightly less mature than the other $69(37 \cdot 4$ weeks $v 39.4$ weeks; $\mathrm{p}<0.01$ ) but the most striking finding was that they had been given more prostaglandin. The babies with no evidence of gastric obstruction $(n=65)$ had received a total mean (SD) cumulative dose of 279 (270) $\mu \mathrm{g} / \mathrm{kg}$ of body weight. The four babies with clinical signs only had had $528(306) \mu \mathrm{g} / \mathrm{kg}$ and the five with proved antral hyperplasia had had $2982(1392) \mu \mathrm{g} / \mathrm{kg}(\mathrm{p}<0.001$ for comparison with the first group and $<0.01$ for comparison with the second). The total duration of infusion was 54 (58) hours in the 'normal stomach' group, $119(60)$ hours in the 'clinical obstruction' group, and 569 (341) in the 'proved atrial hyperplasia' group $(p<0.001$ for comparison of the third with the first group and $<0.05$ for comparison of the third with the second group).

Could the antral mucosal hyperplasia be a consequence of the more severe disease in the babies who needed prostaglandin for longer? That seems unlikely because such changes are not described in chronic hypoxia alone and similar changes have been observed in normal adults given prostaglandin $\mathrm{E}_{2}$ orally. Moreover, two babies in the Toronto series showed regression of the antral hyperplasia after stopping the infusion. The authors conclude that babies given prostaglandin $E_{1}$ at a dose of $0.05 \mu \mathrm{g} / \mathrm{kg}$ of body weight per minute for more than five days should be monitored for evidence of antral obstruction. Nasojejunal feeding may get round the problem but one baby who died had pathology in the duodenum that showed thinning of its muscle layer and was grossly distended with mucus. How many neonatologists will be confident of making an ultrasound diagnosis of atrial mucosal hyperplasia? The cut off point at five days seems arbitrary. It is not clear whether the figures quoted for duration and cumulative dose refer to total dosage or to the dose given when signs of antral obstruction first appeared. The lowest cumulative dose associated with clinical features of gastric obstruction was $222 \mu \mathrm{g} / \mathrm{kg}$ and with antral hyperplasia, 1560 $\mu \mathrm{g} / \mathrm{kg}$. At a rate of $0.05 \mu \mathrm{g} / \mathrm{kg}$ per minute these doses would be given in 74 and 520 hours. Clearly any baby who fails to 'retain' feeds while being treated with prostaglandin will be suspected of developing this complication. 